\title{
The Danish National Acute Leukemia Registry
}

This article was published in the following Dove Press journal:

Clinical Epidemiology

25 October 2016

Number of times this article has been viewed

\section{Lene Sofie Granfeldt \\ Østgård ${ }^{1,2}$ \\ Jan Maxwell Nørgaard' \\ Klas Kræsten Raaschou- Jensen ${ }^{3}$ \\ Robert Schou Pedersen ${ }^{4}$ \\ Dorthe Rønnov-Jessen ${ }^{5}$ \\ Per Troellund Pedersen ${ }^{6}$ \\ Inge Høgh Dufva ${ }^{7}$ \\ Claus Werenberg Marcher ${ }^{8}$ \\ Ove Juul Nielsen ${ }^{9}$ \\ Marianne Tang Severinsen 10,11 \\ Lone Smidstrup Friis ${ }^{9}$ \\ 'Department of Hematology, \\ ${ }^{2}$ Department of Clinical Epidemiology, \\ Aarhus University Hospital, Aarhus, \\ ${ }^{3}$ Department of Hematology, \\ Copenhagen University Hospital, \\ Roskilde, ${ }^{4}$ Department of Medicine, \\ Holstebro Hospital, Holstebro, \\ ${ }^{5}$ Department of Hematology, Vejle \\ Hospital, Vejle, ' $D e p a r t m e n t$ of Medicine, \\ Esbjerg Hospital, Esbjerg, ${ }^{7}$ Department \\ of Hematology, Copenhagen University \\ Hospital, Herlev, ${ }^{8}$ Department of \\ Hematology, Odense University \\ Hospital, Odense, ${ }^{9}$ Department of \\ Hematology, The National University \\ Hospital, Rigshospitalet, Copenhagen, \\ ${ }^{10}$ Department of Hematology, Aalborg \\ University Hospital, Aalborg, Denmark, \\ "Department of Clinical Medicine, \\ Aalborg University, Aalborg, Denmark}

Correspondence: Lene Sofie Granfeldt Østgård

Department of Hematology,

Aarhus University Hospital, Tage-Hansens

Gade 2, DK-8000 Aarhus C,

Denmark

Tel +45 29728 I 27

Fax +4578467599

Email lenoestg@rm.dk
Aim of database: The main aim of the Danish National Acute Leukemia Registry (DNLR) was to obtain information about the epidemiology of the hematologic cancers acute myeloid leukemia (AML), acute lymphoblastic leukemia (ALL), and myelodysplastic syndrome (MDS).

Study population: The registry was established in January 2000 by the Danish Acute Leukemia Group and has been expanded over the years. It includes adult AML patients diagnosed in Denmark since 2000, ALL patients diagnosed since 2005, and MDS patients diagnosed since 2010. The coverage of leukemia patients exceeds $99 \%$, and the coverage of MDS patients is currently $90 \%$.

Main variables and descriptive data: Approximately, $250 \mathrm{AML}$ patients, 25 ALL patients, and 230 MDS patients are registered in the DNLR every year. In January 2015, the registry included detailed patient characteristics, disease characteristics, treatment characteristics, and outcome data on more than 3,500 AML, 300 ALL, and 1,100 MDS patients. Many of the included prognostic variables have been found to be of high quality including positive predictive values and completeness exceeding $90 \%$. These variables have been used in prognostic observational studies in the last few years. To ensure this high coverage, completeness, and quality of data, linkage to the Danish Civil Registration System and the Danish National Registry of Patients, and several programmed data entry checks are used.

Conclusion: The completeness and positive predictive values of the leukemia data have been found to be high. In recent years, the DNLR has shown to be an important high-quality resource for clinical prognostic research.

Keywords: data quality, registries, population-based, acute myeloid leukemia, acute lymphoblastic leukemia, myelodysplastic syndrome

\section{Introduction}

The Danish National Acute Leukemia Registry (DNLR) includes adult patients with acute myeloid leukemia (AML), acute lymphoblastic leukemia (ALL), and myelodysplastic syndrome (MDS).

The aim of the registry is to gain insight into the epidemiology of these cancers, to evaluate treatment responses, to compare results between geographical regions of Denmark, and, through research, to identify prognostic and predictive factors for outcome. One ultimate aim is to improve the quality of treatment and care for acute leukemia and MDS patients.

The DNLR has been a part of the Danish Hematological Database since 2005. Reporting of patient data for the aforementioned diagnoses is mandatory, and obtainment of patient consent is not required. Financial support for the registry depends directly on submit your manuscript | www.dovepress.com

Dovepress

http://dx.doi.org/10.2147/CLEP.S99460
Clinical Epidemiology 2016:8 553-560 (Thematic series on clinical quality databases in Denmark) $\mathbf{5 5 3}$ (c) (i) (5) 2016 Østgard et al. This work is published and licensed by Dove Medical Press Limited. The full terms of this license are available at https://www.dovepress.com/terms. cC. you hereby accept the Terms. Non-commercial uses of the work are permitted without any further permission from Dove Medical Press Limited, provided the work is properly attributed. For permission for commercial use of this work, please see paragraphs 4.2 and 5 of our Terms (https://www.dovepress.com/terms.php). 
registration completeness and coverage. The steering committee for the registry is required to publish an annual report based on specific quality indicators. The indicators are data completeness; 30-, 180-day, 1-, 3-, and 5-year mortality; time from diagnosis to treatment initiation (TTT); and proportions of patients achieving a complete remission (CR), included in clinical trials, and with a cytogenetic evaluation at diagnosis. ${ }^{1}$

\section{Study population}

Acute leukemias are highly aggressive blood cancers, arising from hematopoietic stem cells or committed progenitor cells.
The acute leukemia is classified as myeloid or lymphoblastic leukemia (AML or ALL) depending on origin. Both AML and ALL are characterized by rapid outgrowth of leukemic cells that disrupt the production of normal blood cells. This enhances the risks of anemia, life-threatening infections, and bleeding complications. Prognostic factors, types of treatment, and prognosis differ between the two subtypes. In AML patients, the three most important prognostic factors are age, cytogenetic alterations, and performance status (PS) (Figure 1A and B). ${ }^{2}$ The survival in younger ALL patients has improved over time, but despite the development of
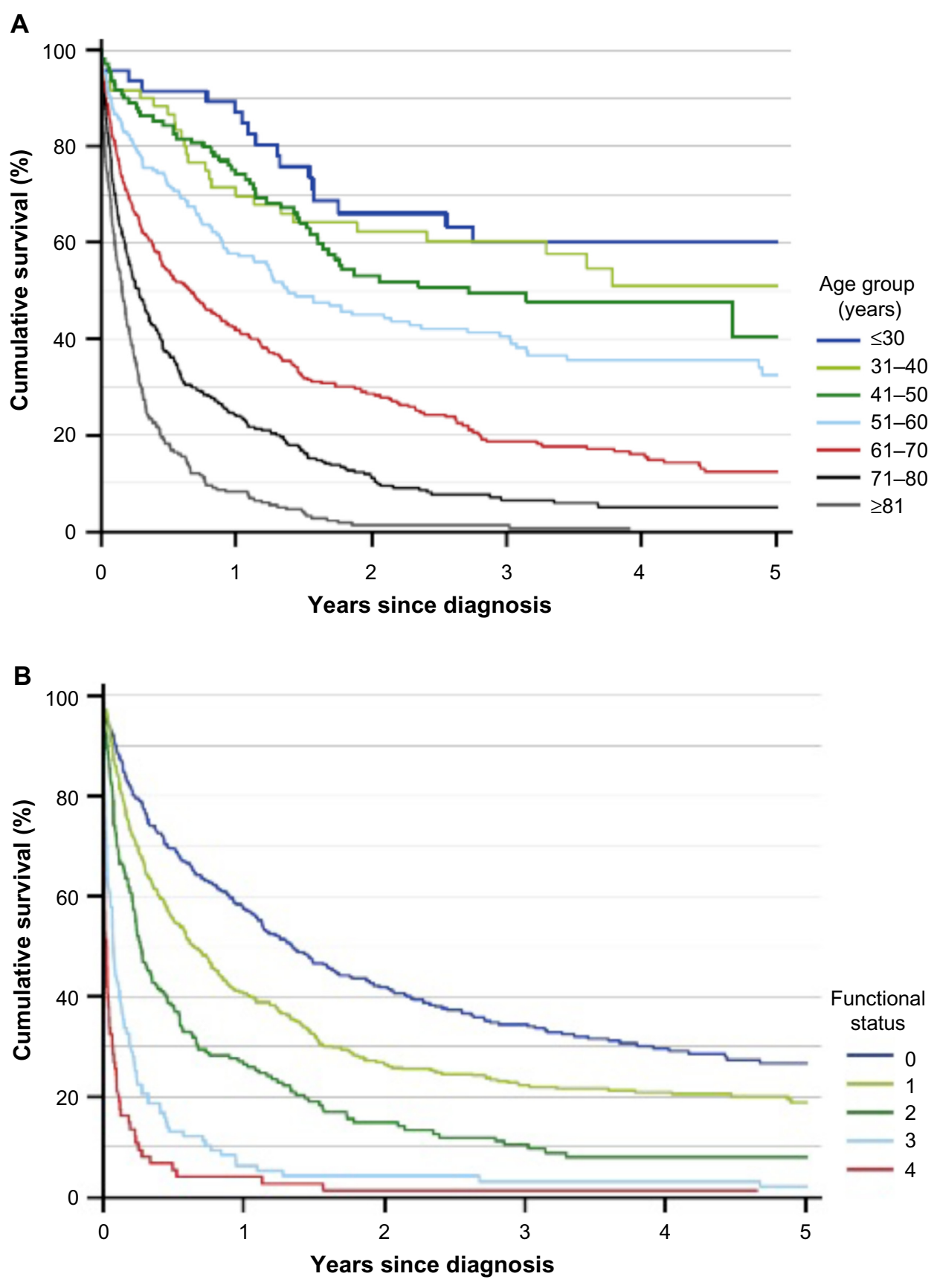

Figure I (Continued) 

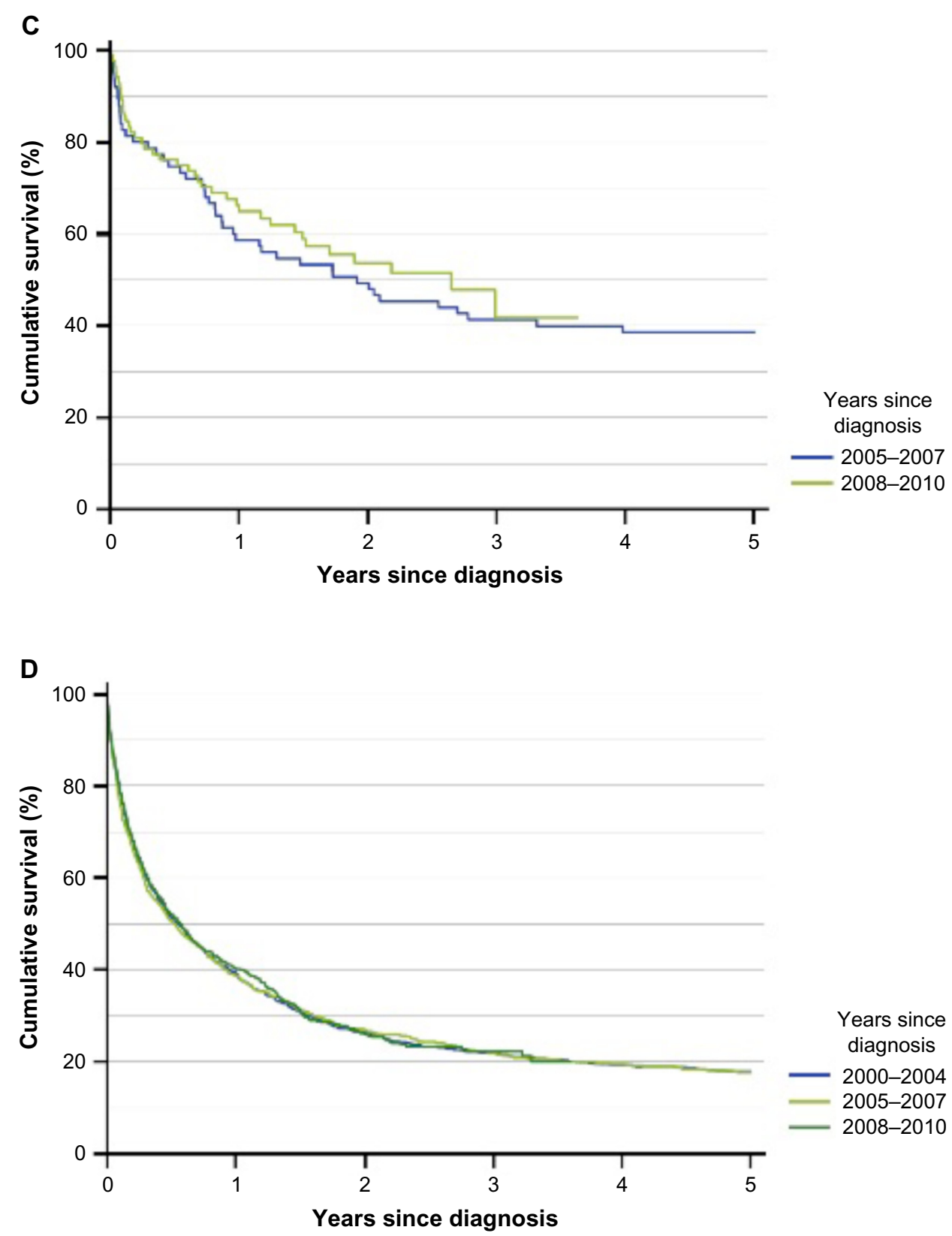

Figure I Survival in Danish AML and ALL patients registered in the Danish National Acute Leukemia Registry.

Notes: (A) Survival in AML patients, by age group; (B) survival in AML patients, by functional status (WHO performance status score); (C) survival in ALL patients, by years since diagnosis ( $n=159$ ); and (D) survival in AML patients (diagnosed between 2005 and 2010), by years since diagnosis ( $n=2,398$ ). Data from the Annual Leukemia Report, 20I0. ${ }^{4}$

Abbreviations: AML, acute myeloid leukemia; ALL, acute lymphoblastic leukemia; WHO, World Health Organization.

new treatment regimens for AML, survival rates for AML patients have not changed significantly over more than a decade (Figure 1C and D).

MDS also arises from myeloid stem cells or committed progenitor cells, and is associated with ineffective production and dysfunction of the normal blood cells. The spectrum of MDS ranges from light anemia to affecting all the three hematopoietic cell lines. ${ }^{2}$ Treatment principles vary from supportive care only (use of blood products, antibiotics, and growth factors), to low-dose chemotherapy, and to intensive
AML-like remission-inducing chemotherapy in patients with increasing blast counts progressing to AML. Overall survival and time to progression to AML can be estimated using the original or revised International Prognostic Scoring System. ${ }^{3}$

The Danish population, $\sim 5.7$ million people,${ }^{4}$ is guaranteed free access to tax-supported medical care provided by the public health care system. Approximately, 250 new cases of AML, 25-35 of ALL, and 200-250 of MDS are diagnosed annually. The treatment takes place within ten 
specialized hematological departments. Six of these departments offer intensive therapy to AML and ALL patients, though treatment of Philadelphia chromosome-negative ALL patients younger than 45 years is centralized at three centers. MDS patients are treated at all ten departments. Two centers perform allogeneic hematopoietic stem cell transplantation in ALL, AML, and MDS patients.

The Danish Society of Hematology established the DNLR in 2000. Since then, all adult ( $>15$ years) AML patients diagnosed in Denmark have been recorded. Since January 2005, adult patients diagnosed with ALL have also been included. In 2010, a separate registry for newly diagnosed cases of MDS was established. Before then, only cases of advanced MDS that were treated using AML protocols were recorded in the leukemia registry. ${ }^{1}$ Since the beginning of registration, more than 3,500 AML patients, 300 ALL patients, and 1,100 MDS patients diagnosed before January 1, 2015 have been registered in the DNLR. The continuing registration annually expands the registry with $\sim 250$ AML patients, 25 ALL patients, and $230 \mathrm{MDS}$.

\section{Main variables}

The DNLR uses standardized web-based registration forms to collect data and the system allows programmed data entry checks. Lists of patients newly diagnosed with AML, ALL, or MDS in the Danish National Registry of Patients (DNRP) ${ }^{5}$ are sent to each hematological department for a confirmation of the diagnosis. If correct, additional data are entered in the registry. For these purposes, medical records including pathology records (Patobank) ${ }^{6}$ are used. To ensure high coverage and completeness of data, the registry is linked to the Danish Civil Registration System ${ }^{7}$ and the DNRP every 3 months.

For AML and ALL patients, up to four registration forms are completed during the disease course of each patient

Table I Data recorded on registration forms used by the Danish National Acute Leukemia Registry

Registration form and time of registration
Acute leukemia (AML, ALL)
Registration form
At diagnosis
From 201 I, the cytogenetic details are included in a separate registration
form

\section{Treatment registration form}

After completed first treatment

Only completed in chemotherapy-treated patients

\author{
Variables \\ Name, civil registration (CPR) number, and demographic data \\ Diagnosis according to WHO (2008)/ICD-10 \\ Date of diagnosis and date of first visit to a health care unit \\ Prior hematological or solid cancer (specified, if present) \\ Prior treatment with radio- or chemotherapy \\ WHO Performance Status Score (WHO PS) \\ Height and body weight \\ Presence of extramedullary leukemia (EML) (specified, if present) \\ FAB-type, blast percentage in the blood and bone marrow \\ Results of cytogenetic evaluation (conventional cytogenetics and FISH) \\ Leukocyte and platelet counts and level of lactate dehydrogenase (LDH) \\ Planned chemotherapy (yes/no) \\ Date of initiated treatment/decision of "no treatment" \\ Treatment intent (palliative or curative) \\ Date of first initiation of treatment \\ Clinical trial participation (yes, no, and specified) \\ For each cycle of combination chemotherapy, if given: \\ Date of initiation, type, and dose \\ Classification of bone marrow response \\ Date of evaluation \\ Transplantation (yes/no) \\ If yes, date of transplantation \\ Type of transplantation (myeloablative, reduced intensity conditioning, \\ or autologous) \\ Date of relapse \\ Treatment intent (palliative or curative) \\ For each cycle of combination chemotherapy, if given: \\ Date of initiation, type, and dose \\ Classification of bone marrow response \\ Date of evaluation
}


Table I (Continued)

\begin{tabular}{|c|c|}
\hline Registration form and time of registration & Variables \\
\hline \multicolumn{2}{|l|}{ Acute leukemia (AML, ALL) } \\
\hline \multicolumn{2}{|l|}{ Follow-up registration form } \\
\hline & Status (dead/alive) \\
\hline \multirow[t]{2}{*}{ At death or termination of follow-up as an outpatient } & Date of death or end of follow-up \\
\hline & Cause of death \\
\hline \multicolumn{2}{|l|}{ Myelodysplastic syndrome (MDS) } \\
\hline Registration form & Name, civil registration (CPR) number, and demographic data \\
\hline \multirow[t]{13}{*}{ At diagnosis } & MDS diagnosis according to WHO (2008)/ICD-I0 \\
\hline & Cytopenia \\
\hline & Anemia $(<6.2 \mathrm{mmol} / \mathrm{L})(\mathrm{Y} / \mathrm{N})$ \\
\hline & Thrombocytopenia $\left(<100 \times 10^{9} / \mathrm{L}\right)(\mathrm{Y} / \mathrm{N})$ \\
\hline & Neutropenia $(<\mathrm{I} .8 \mathrm{mia} / \mathrm{L})(\mathrm{Y} / \mathrm{N})$ \\
\hline & Results of cytogenetic evaluation \\
\hline & Good Risk (-Y, del5q, del20q) \\
\hline & Intermediate risk (not classified as good risk or poor risk) \\
\hline & Poor risk (chromosome 7 aberrations or complex karyotype \\
\hline & $[>3$ changes $])$ \\
\hline & Blast percentage in the blood and bone marrow \\
\hline & Prior hematological or disease or cancer (specified, if present) \\
\hline & Primary treatment \\
\hline \multirow[t]{15}{*}{ Treatment registration form } & Transfusion $(\mathrm{Y} / \mathrm{N})$ \\
\hline & Erythropoietin $(\mathrm{Y} / \mathrm{N})$ \\
\hline & Granulocyte colony-stimulating factors $(\mathrm{Y} / \mathrm{N})$ \\
\hline & Iron-chelating agents $(\mathrm{Y} / \mathrm{N})$ \\
\hline & Hydroxyurea $(\mathrm{Y} / \mathrm{N})$ \\
\hline & Demethylating agents $\left(\right.$ Azacytidin $\left.^{\circledR}\right)(\mathrm{Y} / \mathrm{N})$ \\
\hline & Remission-induction-like chemotherapy $(\mathrm{Y} / \mathrm{N})$ \\
\hline & Immunotherapy $(\mathrm{Y} / \mathrm{N})$ \\
\hline & Lenalidomide? (Y/N) \\
\hline & Others $(\mathrm{Y} / \mathrm{N})$ \\
\hline & Progression to acute leukemia $(\mathrm{Y} / \mathrm{N})$ \\
\hline & If yes, date of progression \\
\hline & Clinical trial participation $(\mathrm{Y} / \mathrm{N})$ \\
\hline & Allogeneic stem cell transplantation $(\mathrm{Y} / \mathrm{N})$ \\
\hline & If yes (date and type of transplantation) \\
\hline Follow-up registration form & Status (dead/alive) \\
\hline \multirow[t]{2}{*}{ At death or termination of follow-up as an outpatient } & Date of death or end of follow-up \\
\hline & If alive, name of hospital department continuing treatment and \\
\hline
\end{tabular}

Note: Adapted with permission of Dove Medical Press Ltd., from Data quality in the Danish National Acute Leukemia Registry: a hematological data resource, Østgård L, Nørgaard J, Severinsen M, et al, Clin Epidemiol, 2013;5:335-344, ${ }^{8}$ Copyright $($ C) 2009; permission conveyed through Copyright Clearance Center, Inc.

Abbreviations: AML, acute myeloid leukemia; ALL, acute lymphoblastic leukemia; CPR, civil registration number; ICD, International Classification of Diseases; FISH, fluorescence in situ hybridization; WHO, World Health Organization; WHO PS, World Health Organization performance status score; Y, yes; N, no; FAB, French-AmericanBritish.

(Table 1). Depending on treatment schedule and clinical course, data on more than 150 variables (patient- and leukemia-related, treatment- and outcome-related) can be recorded for each patient. The first form is completed at diagnosis. To optimize data quality, the clinical cytogeneticist enters cytogenetic details obtained at diagnosis. A second form is completed following first-line treatment in chemotherapytreated patients and includes information about allogeneic transplantation performed in first CR. A third form is completed in case of relapse. A fourth form is completed at death or termination of clinical follow-up.
For MDS patients, up to three registration forms are completed: a registration form at diagnosis, a treatment form, and a form at death or termination of follow-up.

We recently performed a validation study of the quality of AML registrations in the DNLR. ${ }^{8}$ In that study, the coverage of the DNLR was found to be $99.6 \%$ (95\% confidence interval [CI] 99.3-99.8) with the DNRP used as a reference. We validated DNLR information in a random sample of 260 patients, and found completeness to exceed $90 \%$ in 23 out of 30 selected variables. The positive predictive values (PPVs) were higher than $95 \%$ for 23 variables, and higher than $90 \%$ 
Table 2 Completeness and PPVs of 30 variables from the DNLR

\begin{tabular}{|c|c|c|c|}
\hline Variable & $\begin{array}{l}\text { Number of correctly } \\
\text { coded records/ } \\
\text { number of relevant } \\
\text { records reviewed }\end{array}$ & $\begin{array}{l}\text { Completeness (\%) } \\
(95 \% \mathrm{Cl})\end{array}$ & $\begin{array}{l}\text { PPV (\%) } \\
(95 \% \mathrm{Cl})\end{array}$ \\
\hline Diagnosis & $244 / 245$ & $100(99.0-100)$ & $99.6(98.1-100)$ \\
\hline Time of diagnosis ( \pm 24 hours) & $219 / 245$ & $100(99.0-100)$ & $89.4(85.1-92.8)$ \\
\hline Time of diagnosis ( \pm 6 days) & $236 / 245$ & & $96.3(93.4-98.2)$ \\
\hline Cytogenetic result & $220 / 231$ & $99.6(98.0-99.9)$ & $95.2(91.9-97.4)$ \\
\hline Cytogenetic result, specified & $224 / 231$ & 99.1 (97.3-99.8) & $97.0(94.4-98.6)$ \\
\hline Prior hematological disease & $231 / 240$ & $98.0(96.6-99.2)$ & $96.3(93.2-98.1)$ \\
\hline Prior hematological disease, specified & $42 / 44$ & $83.0(71.3-91.3)$ & $95.5(86.2-99.0)$ \\
\hline Prior cancer, other than hematological & $182 / 186$ & $75.9(70.3-80.1)$ & $97.8(95.0-99.3)$ \\
\hline Missing categorized as no prior cancer & $238 / 245$ & $100(99.0-100)$ & $97.1(94.5-98.7)$ \\
\hline Prior cancer, specified & $16 / 17$ & $60.7(42.3-77.0)$ & $94.1(75.7-99.4)$ \\
\hline Prior chemotherapy & $234 / 244$ & $100(99.0-100)$ & $95.9(92.9-97.9)$ \\
\hline Prior radiotherapy & $239 / 244$ & $100(99.0-100)$ & $98.0(95.6-99.2)$ \\
\hline WHO PS & $236 / 24 I$ & $100(99.0-100)$ & $97.9(95.5-99.2)$ \\
\hline Extramedullary leukemia & $217 / 230$ & $96.2(93.2-98.1)$ & $94.3(90.8-96.8)$ \\
\hline Extramedullary leukemia, specified & $27 / 29$ & $72.5(57.5-84.4)$ & $93.1(79.7-98.6)$ \\
\hline White blood cell count $(\mathrm{WBC})\left(I \times 10^{9} / \mathrm{L}\right)$ & $218 / 232$ & $97.9(95.4-99.2)$ & $94.0(90.3-96.5)$ \\
\hline Platelet count $\left(I \times 10^{9} / \mathrm{L}\right)$ & $211 / 231$ & $97.5(94.9-98.9)$ & $91.3(87.2-94.5)$ \\
\hline Lactate dehydrogenase (U/L) & $|57 / 16|$ & $67.9(61.8-73.6)$ & $97.5(94.2-99.2)$ \\
\hline Weight & $216 / 216$ & $90.4(86.2-93.6)$ & $100(98.8-100)$ \\
\hline Height & $214 / 215$ & $90.0(85.7-93.2)$ & $99.5(97.8-99.9)$ \\
\hline Curative intent? & $229 / 233$ & $97.5(94.9-98.9)$ & $98.3(96.0-99.4)$ \\
\hline Protocol participation? & $116 / 119$ & $94.4(89.4-97.5)$ & $97.5(93.4-99.3)$ \\
\hline Time of initiated treatment & $205 / 206$ & $98.6(96.2-99.6)$ & $99.5(97.8-99.8)$ \\
\hline $\begin{array}{l}\text { First course of induction chemotherapy, } \\
\text { specified }\end{array}$ & $194 / 204$ & 97.1 (94.2-98.8) & $95.1(91.5-97.5)$ \\
\hline $\begin{array}{l}\text { Dose of first course of induction } \\
\text { chemotherapy, specified }\end{array}$ & $203 / 204$ & 97.1 (94.2-98.8) & $99.5(97.7-99.9)$ \\
\hline $\begin{array}{l}\text { Bone marrow response, after first course of } \\
\text { chemotherapy }\end{array}$ & $202 / 205$ & 97.1 (94.2-98.8) & $98.5(96.1-99.6)$ \\
\hline Second course of induction chemotherapy, specified & $195 / 202$ & $96.2(92.9-98.2)$ & $96.5(93.3-98.4)$ \\
\hline $\begin{array}{l}\text { Dose of second course of induction } \\
\text { chemotherapy, specified }\end{array}$ & $201 / 203$ & $96.7(93.6-98.5)$ & $99.0(96.9-99.8)$ \\
\hline $\begin{array}{l}\text { Bone marrow response, after second course of } \\
\text { chemotherapy }\end{array}$ & $197 / 200$ & $95.2(91.7-97.5)$ & $98.5(96.1-99.6)$ \\
\hline Relapse? (if yes, date specified) & $|57 / 16|$ & $94.7(90.6-97.3)$ & $97.5(94.2-99.2)$ \\
\hline Extramedullary leukemia at relapse? & $53 / 55$ & $88.7(79.1-94.8)$ & $96.4(88.9-99.2)$ \\
\hline Cause of death & $136 / 146$ & $81.1(74.9-86.3)$ & $93.2(88.2-96.4)$ \\
\hline
\end{tabular}

Note: Adapted with permission of Dove Medical Press Ltd., from Data quality in the Danish National Acute Leukemia Registry: a hematological data resource, Østgård L, Nørgaard J, Severinsen M, et al, Clin Epidemiol, 2013;5:335-344, ${ }^{8}$ Copyright (C) 2009; permission conveyed through Copyright Clearance Center, Inc.

Abbreviations: PPV, positive predictive value; DNLR, Danish National Acute Leukemia Registry; WHO PS, World Health Organization performance status score; Cl, confidence interval.

for 29 of 30 variables (Table 2). The quality of data registered on ALL patients is not expected to vary, since the variables are identical and the same physicians are entering data. The coverage of the MDS registry is estimated to be $90 \%$, and a validation study of the individual variables has been planned for MDS data to be performed prior to use of data for research purposes.

\section{Follow-up}

In leukemia patients, treatment responses are registered according to international guidelines. ${ }^{9}$ For patients achieving CR, relapses are registered. For all patients, date of death or end of follow-up due to other causes is registered in the DNLR. Data are cross-linked to the Danish Civil Registration System to ensure accurate information on vital status. Based on these variables, leukemia-free and overall survival can be calculated. Since both ALL and AML are aggressive cancers and MDS patients in general are older, a high proportion of patients die within 1-5 years of follow-up. (Overall survival rates for AML and ALL patients are shown in Figure 1.) By December 2013, the DNLR consisted of data on 3,055 AML patients (excluding acute promyelocytic leukemia). In September 2014, these 
patients had a combined follow-up time of 5,296 years and a mean follow-up time of 188 days; 512 days in intensive therapy patients (interquartile range [IQR]: 179-1,374) and 64 days in palliative intent patients (IQR: 19-184).

\section{Examples of research}

The DNLR has been used for various studies in which it has been merged with local databases (transplantation and clinical trial office databases) and national registries (the Danish Civil Registration System, DNRP, the Danish Cancer Registry).

In one study, the registry was used to investigate the impact of patient and disease characteristics on TTT and to assess the effect of TTT on treatment response (CR) and survival. ${ }^{10}$

In a second study, data were used to examine how treatment intent varies by comorbidity and functional status (World Health Organization performance status score [WHO PS]) and to determine the prognostic impact of comorbidity and PS on achievement of CR, early death, and long-term mortality. ${ }^{11}$

In a third study, data were used to estimate frequencies of therapy-related and secondary AML (MDS and non-MDS) overall and over time; they were also used to describe differences in characteristics, and outcome between intensively treated secondary and therapy-related AML (depending on prior hematological disease or cytotoxic therapy) and de novo AML patients. ${ }^{12}$

In a fourth study, the registry was used to estimate the patient accrual rates of clinical AML trials in Denmark, to describe the difference in patient and disease characteristics as well as outcome between patients treated according to clinical trials and those treated outside clinical trials. ${ }^{13}$

In an ongoing study, researchers are investigating the impact of body mass index (BMI) on prognosis. Data on smoking and alcohol consumption are obtained from medical records and will be used to investigate the impact of lifestyle factors on outcome.

Finally, the importance of the quality of CR with reconstitution of bone marrow function is being investigated using data from the National Danish Transfusion Database.

ALL and MDS data have not yet been used for research, as the number of patients is relatively small and the followup time is short. A Nordic collaboration aims to merge data between national MDS registries, thereby expanding the study population.

\section{Conclusion}

The DNLR includes patient and disease characteristics, as well as outcome data on MDS and acute leukemia patients. The completeness and PPVs of the data are high, and the registry captures more than $99.5 \%$ of AML patients. So far, these high-quality data have been used for large nationwide prognostic studies of AML. Within the next 5 years, the follow-up time for MDS and ALL patients will allow these data to be explored. In conclusion, the DNLR has shown to be a valuable resource for clinical research of acute leukemia.

\section{Acknowledgments}

We wish to thank all hematologists who carefully report clinical data to the registry. Also, we appreciate the dedicated work of Secretary Kirsten Hansen, Aarhus University Hospital, and of the data coordinator, Dr Peter Brown, Copenhagen University Hospital. This paper was funded by the Program for Clinical Research Infrastructure (PROCRIN) established by the Lundbeck Foundation and the Novo Nordisk Foundation and administered by the Danish Regions.

\section{Disclosure}

The registry is administered by the Registry Support Centre of Epidemiology and Biostatistics (East) and the Registry Support Centre of Clinical Quality and Health Informatics (East). Lene Sofie Granfeldt Østgård is supported by the Danish Cancer Society. The other authors report no conflicts of interest in this work.

\section{References}

1. Akut Leukæmi Gruppen. [Annual Report from the Leukemia Registry] Arsrapport. Århus, Denmark: Akut Leukæmi Gruppen; 2012.

2. Swerdlow SH, Campo E, Harris NL, editors. WHO Classification of Tumours of Haematopoietic and Lymphoid Tissues. 4th ed. Lyon, France: International Agency for Research on Cancer (IARC); 2008.

3. Malcovati L, Hellstrom-Lindberg E, Bowen D, et al. Diagnosis and treatment of primary myelodysplastic syndromes in adults: recommendations from the European LeukemiaNet. Blood. 2013;122(17):2943-2964.

4. Population and elections - StatBank Denmark - data and statistics [webpage on the Internet]. Available from: http://www.statbank.dk. Accessed January 20, 2016

5. Lynge E, Sandegaard JL, Rebolj M. The Danish National Patient Register. Scand J Public Health. 2011;39(Suppl 7):30-33.

6. Bjerregaard B, Larsen OB. The Danish Pathology Register. Scand J Public Health. 2011;39(Suppl 7):72-74.

7. Pedersen CB. The Danish Civil Registration System. Scand J Public Health. 2011;39( Suppl 7):22-25.

8. Østgård L, Nørgaard J, Severinsen M, et al. Data quality in the Danish National Acute Leukemia Registry: a hematological data resource. Clin Epidemiol. 2013;5:335-344.

9. Cheson BD, Bennett JM, Kopecky KJ, et al. Revised recommendations of the International Working Group for Diagnosis, Standardization of Response Criteria, Treatment Outcomes, and Reporting Standards for Therapeutic Trials in Acute Myeloid Leukemia. J Clin Oncol. 2003;21(24):4642-4649.

10. Østgård L, Nørgaard J, Sengeløv H, et al. Impact of chemotherapy delay on short- and long-term survival in younger and older AML patients: a Danish population-based cohort study. Leukemia 2014;28(9):1926-1929.

11. Østgård L, Nørgaard J, Sengeløv H, et al. Comorbidity and performance status in acute myeloid leukemia patients: a nation-wide populationbased cohort study. Leukemia. 2015;29(3):548-555. 
12. Østgård L, Medeiros B, Sengeløv H, et al. Epidemiology and clinical significance of secondary and therapy-related acute myeloid leukemia: a national population-based cohort study. J Clin Oncol. 2015; 33(31): 3641-3649.
13. Ostgard LSG, Norgaard M, Sengelov H, et al. Do results from clinical trials in acute myeloid leukemia reflect clinical reality? A Danish national cohort study of 813 patients. ASH Annual Meeting Abstracts. 2012;120(21):1477.

\section{Publish your work in this journal}

Clinical Epidemiology is an international, peer-reviewed, open access, online journal focusing on disease and drug epidemiology, identification of risk factors and screening procedures to develop optimal preventative initiatives and programs. Specific topics include: diagnosis, prognosis, treatment, screening, prevention, risk factor modification,

Submit your manuscript here: http://www.dovepress.com/clinical-epidemiology-journal

\section{Dovepress}

systematic reviews, risk \& safety of medical interventions, epidemiology \& biostatistical methods, and evaluation of guidelines, translational medicine, health policies \& economic evaluations. The manuscript management system is completely online and includes a very quick and fair peer-review system, which is all easy to use. 